\title{
A NAPIN PROMOTER ACTIVATES GENE EXPRESSION IN DEVELOPING SEEDS OF LESQUERELLA FENDLERI
}

\author{
Grace Q. Chen and Jiann-Tsyh Lin \\ Department of Agriculture, Western Regional Research Center, \\ Agricultural Research Service, U.S, 800 Buchanan St., Albany, CA 95710, USA
}

Received 2012-08-21, Revised 2012-09-17; Accepted 2012-09-18

\begin{abstract}
Lesquerella fendleri produces industrial useful Hydroxy Fatty Acids (HFA) in seed oil. To improve oil and HFA of L. fendleri, it is desirable to use of seed-specific promoters to control the expression of target genes by genetic engineering. A seed-specific promoter fragment, -397 to -1 of a napin gene (PnapA) from Brassic napus was isolated by PCR and constructed to a small promoter-testing vector named pGPro4. A nopaline synthase (nos) promoter was used to control the expression of the selectable marker of pGPro4. pGPro4 also contains a bifunctional $\beta$-glucuronidase-enhanced Green Fluorescent Protein (gusA-eGFP) reporter gene that provides visual detection of reporter gene expression using either fluorescence in live cells or histochemical detection of $\beta$-glucuronidase activity. To demonstrate the usefulness of PnapA, L. fendleri was transformed with the pGPro4-PnapA vector. Primary transgenic shoots were generated from explants at an expected frequency of 13 to $23 \%$, indicating that the nos promoter drove sufficient hptII expression to generate hygromycin resistant plants. Five independent transgenic L. fendleri lines were grown to maturity and generated $\mathrm{T}_{1}$ seeds. Segregation analysis of $\mathrm{T}_{1}$ seeds indicated that the transgenic $L$. fendleri lines contain one, two or more integration sites. The gusA-eGFP reporter gene activity was examined in various organs of all these transgenic lines by standard GUS assay. Only seeds showed positive GUS stain, confirming that PnapA confers seed-specific expression in transgenic L. fendleri.
\end{abstract}

Keywords: Lesquerella Fendleri, Napin Promoter, Hygromycin Phosphotransferase II, B-Glucuronidase, Agrobacterium-Mediated Transformation

\section{INTRODUCTION}

Lesquerella fendleri (A. Gray) S. Wats. (Brassicaceae), under development as a new industrial oilseed crop in the southwestern region of the U.S., is valued for its unusual Hydroxy Fatty Acid (HFA). HFAs and derivatives are used as raw materials for numerous industrial products, such as lubricants, plasticizers and surfactants (Caupin, 1997). L. fendleri is amenable to Agrobacterium-mediated transformation (Chen, 2011; Skarjinskaia et al., 2003; Wang et al., 2008), thus genetic transformation provides an alternative means to improve this crop. To engineer oils or fatty acid contents in $L$. fendleri seed, it is preferable to utilize seed specific promoters, to limit the changes of oils and fatty acids to the seed and to avoid the changes in membrane lipids in other parts of the plant. It is known that napins, a group of storage proteins, are tightly regulated by seed developmental process, their synthesis is induced by abscisic acid and restricted to the developing seeds (Crouch and Sussex, 1981; Crouch et al., 1983). The physiological role of napins is to provide the growing seedling with essential nutrients prior to the establishment of the photosynthetic capacity.

Napins are encoded by a multigene family in rapeseed and other Brassica species. One of napins, napA, has been cloned and sequenced (Josefsson et al., 1987) (Genbank accession: J02798). NapA has been demonstrated to be highly expressed in developing seeds (Stalberg et al., 1993) and its promoter could also drive

\section{Corresponding Author: Grace Q. Chen, Department of Agriculture, Western Regional Research Center, Agricultural Research Service, U.S, 800 Buchanan St., Albany, CA 95710, USA Tel: 510-559-5627 Fax: 510-559-5768}


the expression of foreign genes efficiently in the embryos of transgenic plants, including modification of the lipid profile of oilseeds (Broun et al., 1998; Eccleston and Ohlrogge, 1998; Topfer et al., 1995). Based on reports, napA promoter $(-309$ to +45$)$ directs strong reporter gene activity in transgenic tobacco seeds (Stalberg et al., 1993). In the -309 napA promoter, a highly conserved region between positions -152 and -120 is crucial for promoter function

in transgenic rapeseed (Ellerstrom et al., 1996; Stalberg et al., 1996) and tobacco (Ellerstrom et al., 1996). Two cis elements were identified in this region: an ABRE (abscisic acid-responsive element)-like element situated between -148 and -139 and a CA-rich element between -130 and -124 (Ellerstrom et al., 1996). Other cis elements include two RY-repeat motifs bordering a G-box at -78 to -50 and the B-box situated between -152 and -120 (Ezcurra et al., 1999). These seed-specific cis elements are highly conserved seed promoters (Baumlein et al., 1992) and are crucial for seed-specific expression directed by napA, leguminin and glycinin promoters (Baumlein et al., 1992; Ezcurra et al., 1999; Lelievre et al., 1992).

We have cloned and sequenced the upstream regulatory region of napA gene to test the tissue specific expression pattern of this promoter in L. fendleri. We constructed the promoter sequence from -397 to -1 (corresponding to Genbank accession J02798, 708 to 1145) in pGPro4 vector (Chen et al., 2011) (GenBank accessions JN593324). This vector contains a promoterless gusA-eGFP ( $\beta$-glurcuronidase-enhanced Green Fluorescent Protein) reporter gene, a small size plasmid backbone and many unique restriction sites. More importantly, pGPro4 was designed for precise testing an organ-specific promoter. Because in many popular vectors such as pCAMBIA (www.cambia.org) and pGreen (Hellens et al., 2000), one overlooked problem is the use of the CaMV35S promoter with one or more enhancer sequences to drive selectable marker gene expression. When an organ-specific promoter-target gene cassette is placed within a such vector, the enhancer can bidirectionally interfere with the transcription of the target gene as well as nearby genes, affecting the fidelity of the organ-specific gene expression and/or causing unintended misexpression of nearby genes (Yoo et al., 2005; Xie et al., 2001). To avoid this problem, a nopaline sythase promoter (nosP) is used to drive a selectable marker gene, hptII (hygromycin phosphotransferase II), in pGPro4. We report here the construction of the napA promoter to upstream of gusA gene and analysis the tissue specific pattern of this promoter in transgenic L. fendleri carrying this construct.

\section{MATERIALS AND METHODS}

\subsection{Construction of the pGPro4-napa Promoter (pGPro4-PnapA) Binary Vector}

The vector map of the pGPro4 vector was described (Chen et al., 2011) and the annotated sequence is available from Genbank (accession JN593324). The promoter sequence of napA from -397 to -1 was synthesized by using PCR and the genomic DNA of Brassic napus, cultivar svaloefs karab (USDA-ARS germplams accession number PI 535869) as template. The PCR primers, forward 5, GAGCTCCCAATTTATATTCCCAACGGC 3', reverse 5 ,

\section{GAATTCGTGTATGTTTTTAATCTTGTTTGTATTG}

ATG 3' were designed based on the reported napA promoter sequence (GenBank accession J02798) and restriction sites, $S a c I$ and EcoRI were added to facilitate the cloning of the PCR product in pGPro4 vector. The accuracy of $p$ GPro4-PnapA clone was confirmed by sequencing analysis.

\subsection{Plant Material, Bacterial Strain}

The L. fendleri seeds, WCL-LY2 (Dierig et al., 2001), were kindly provided by Dr. Dave Dierig (USDA-ARS, Arid-Land Agricultural Research Center, Maricopa, AZ). Plants were grown in a greenhouse at temperatures between $28^{\circ} \mathrm{C}$ (day) and $18^{\circ} \mathrm{C}$ (night), with supplemental metal halide lighting to provide a 15-hr-day length (1000 to $\left.1250 \mu \mathrm{mol} \mathrm{m}{ }^{-2} \mathrm{sec}^{-1}\right)$. Mature female flowers were hand-pollinated and the seeds were harvested at about 49 days after pollination. An Agrobacterium tumefaciens strain AGL1 (Lazo et al., 1991) carrying binary vector pGPro4-PnapA was used for plant transformation. An AGL1/pGPro4-PnapA culture was started with the inoculation of one clone in 1 $\mathrm{mL}$ Luria Broth (LB, $10 \mathrm{~g} \mathrm{~L}^{-1}$ tryptone, $5 \mathrm{~g} \mathrm{~L}^{-1}$ yeast extract, $5 \mathrm{~g} \mathrm{~L}^{-1}$ sodium chloride, $1 \mathrm{~g} \mathrm{~L}^{-1}$ glucose, $\mathrm{pH} 7$ ) supplemented with $50 \mathrm{mg} \mathrm{L}^{-1}$ kanamycin and $100 \mathrm{mg}$ $\mathrm{L}^{-1}$ carbenicillin shaken at $200 \mathrm{rpm}$ overnight at $28^{\circ} \mathrm{C}$, followed by sub-culturing of $0.1 \mathrm{~mL}$ of the overnight culture in $50 \mathrm{~mL}$ fresh $\mathrm{LB}$ for overnight.

\subsection{Tissue Culture, Transformation and Regeneration}

The previously described protocol (Chen, 2011) was utilized for L. fendleri transformation. In brief, leaves harvested from plants in sterile condition were wounded by scratching slightly on the underside of a leaf and then cultured on Callus and Shoot Induction (CSI) medium. After two days, the leaves were dipped in the half strength MS medium containing AGL1/pGPro4-PnapA 
for five minutes. Following the inoculation, leaves were blotted on sterilized filter paper and transferred to Callus and Shoot Induction (CSI) medium composed of basal medium (BM, half strength MS medium plus $30 \mathrm{~g} \mathrm{~L}^{-1}$ sucrose and $6 \mathrm{~g} \mathrm{~L}^{-1}$ agar, $\mathrm{pH}$ 5.7) supplemented with 1 $\mathrm{mg} \mathrm{L}^{-1}$ 6-BENZYLAMINOPURINe (BA) and $0.1 \mathrm{mg}$ $\mathrm{L}^{-1}$ 1-Naphthaleneacetic Acid (NAA). After incubating the infected leaves in the growth chamber for 2 days, the leaves were cut into $5 \mathrm{~mm}$ segments and cultured on CSI media plus $25 \mathrm{mg} \mathrm{L}^{-1}$ hygromycin (hyg) for transgenic selection and $100 \mathrm{mg} \mathrm{L}^{-1}$ timentin for inhibiting the Agrobaterium growth. In 6-8 weeks, yellow-greenish hygromycin resistant calli started to appear on the leaf segments. The calli were then transferred to a timentin-free subculture medium CSI+ (CSI with hygromycin increased to $50 \mathrm{mg} \mathrm{L}^{-1}$ ). Green shoots were developed from the calli on CSI+ medium in about 2-4 weeks after the transfer. To eliminate chimeras, each shoot was cut into small pieces (about $1 \times 1 \mathrm{~mm}$ ) and placed on the CSI+ medium for shoot-regeneration. After 4 rounds of successive regenerations, shoots were sub-cultured on BM plus $1 \mathrm{mg} \mathrm{L}^{-1} \mathrm{BA}, 1 \mathrm{mg} \mathrm{L}^{-1}$ Indole-3-Butyric Acid (IBA) and $50 \mathrm{mg} \mathrm{L}^{-1}$ hyg for multiplication. Shoots $10-15 \mathrm{~mm}$ in length were transferred to rooting medium (BM plus $1 \mathrm{mg} \mathrm{L}^{-1}$ IBA and $50 \mathrm{mg} \mathrm{L}^{-1}$ hyg). When a shoot developed 2-3 roots (usually in 3-5 weeks), it was then transferred to a Magenta box (Sigma, St. Louis, Mo) containing sterilized peat-vermiculite growth mixture (Sunshine mix \#4, Planet Natural, Bozeman, MT) pre-soaked with $1 \mathrm{mg}$ $\mathrm{L}^{-1}$ IBA water solution. After 8-10 weeks in the growth mixture, well-developed primary plants showing 8-12 normal leaves and 2-3 inch height were transferred to a 6-inch pot and placed under a transparent plastic cover for the first 2 weeks for acclimation in the greenhouse.

\subsection{Detection of $\beta$-Glucuronidase Gene Activity}

Developing seeds at different stages were dissected out and the Histochemical GUS assays (gusA gene activity) were performed using the Jefferson method (Jefferson et al., 1987). The assay solution contained 0.5 $\mathrm{mM}$ potassium ferrocyanide, $0.3 \%(\mathrm{v} / \mathrm{v})$ triton $\mathrm{X}-100$ and $1 \mathrm{mg} \mathrm{mL}$ 5-bromo-4-chloro-3-indolyl-Dglucuronide (X-gluc) in $50 \mathrm{mM}$ phosphate buffer, pH7.0. Samples were incubated at $37^{\circ} \mathrm{C}$ overnight in the assay solution and then transferred to $70 \%$ ethanol. GUS staining images were documented using a Leica dissecting microscope (Leica micro-system Ltd., CH-9435 Heerbrugg, Switzerland) equipped with a digital camera. Mature seeds harvested from primary transgenic plants or Wild type (Wt) seeds were surface-sterilized in a $0.25 \%$ (v/v) sidium hypochlorite solution for $15 \mathrm{~min}$ followed by five rises in sterile deionized water. Wt seeds were germinated on Germination Medium (GM) containing half strength of MS salts and $0.6 \%$ agar. Transgenic seeds were germinated on GM supplemented with $0.5 \%$ sucrose, 50 $\mathrm{mg} \mathrm{L}^{-1}$ hyg and $0.6 \%$ agar. Two-week old seedlings were tested for GUS activity as described above.

\section{RESULTS AND DISCUSSION}

\subsection{Fendleri Transformation with the pGPro4-PnapA Vector}

To examine the functionality of the PnapA, we constructed the pGPro4-PnapA plasmid by ligation of a 406 bp promoter PCR fragment (material and method) upstream of the gusA-eGFP reporter gene and tested it in L. fendleri by Agrobacterium-mediated transformation using a previously described protocol (Chen, 2011). In three separate experiments, the percentage of primary hygromycin resistant shoots generated from the explants ranged from $13-23 \%$ (Table 1). The frequency of primary shoot regeneration is lower than that of 22-60\% when a pCAMBIA plasmid was used (Chen, 2011), but still gave rise a sufficient number of transformants. Five independent primary transgenic L. fendleri plants were grown to maturity in the greenhouse to produce next generation $\left(T_{1}\right)$ seeds. The number of unlinked integration sites was estimated from the segregation of hyg-resistant $\left(\right.$ hyg $\left.^{\mathrm{R}}\right) \mathrm{T}_{1}$ seedlings. The analysis showed that transformation with $p$ GPro4-PnapA construct gave rise to collection of plants containing different numbers of integration sites, from one to more than two (Table 2). The result is similar to what we observed when a pCAMBIA plasmid was used (Chen, 2011). The presence of PnapA was verified by PCRs with PnapA specific primers. All lines tested showed presence of the PnapA (data not shown).

Table 1. Number of calli and shoots produced in leaf segments

\begin{tabular}{lllll}
\hline $\begin{array}{l}\text { Expt. } \\
\text { No. }\end{array}$ & $\begin{array}{l}\text { No. of } \\
\text { segments }\end{array}$ & $\begin{array}{l}\text { No. of } \\
\text { calli }^{\mathrm{a}}\end{array}$ & $\begin{array}{l}\text { No. of } \\
\text { shoots }^{\mathrm{b}}\end{array}$ & Shoot (\%) \\
\hline 1 & 30 & 7 & 6 & 20 \\
2 & 30 & 5 & 4 & 13 \\
3 & 30 & 9 & 7 & 23 \\
\hline
\end{tabular}

${ }^{a}$; The number was scored at the 8 th week after placing the explants on CSI medium plus $25 \mathrm{mg} \mathrm{L}^{-1}$ hygromycin and 100 $\mathrm{mg} \mathrm{L}^{-1}$ timentin ${ }^{\mathrm{b}}$; The number was scored at the 4 th week of subculture on CSI medium plus $50 \mathrm{mg} \mathrm{L}^{-1}$ hygromycin 
Table 2. $\mathrm{T} 1$ progeny numbers and segregation ratios of hygromycin-resistant $\left(\right.$ hyg $\left.^{\mathrm{R}}\right)$ and hygromycinsensitive (hyg ${ }^{S}$ ) phenotype

\begin{tabular}{lllll}
\hline & $\begin{array}{l}\text { Total No } \\
\text { of seeds }\end{array}$ & $\begin{array}{l}\text { No of } \\
\text { germinated }\end{array}$ & $\begin{array}{l}\text { hyg }^{\mathrm{R}}: \text { hyg }^{\mathrm{S}} \\
\text { seedlings }\end{array}$ & $\begin{array}{l}\text { No of } h p t I I \\
\text { gene insertion }\end{array}$ \\
\hline 1 & 42 & 39 & $30: 9$ & 1 \\
2 & 48 & 45 & $33: 12$ & 1 \\
3 & 53 & 50 & $47: 3$ & 2 \\
4 & 38 & 37 & $35: 2$ & $\geq 2$ \\
5 & 31 & 29 & $29: 0$ & $>2$ \\
\hline
\end{tabular}

Seeds were sterilized and placed on GM plus $50 \mathrm{mg} \mathrm{L}^{-1}$ hyg, hyg $^{\mathrm{R}}$ or hyg ${ }^{\mathrm{S}}$ seedlings were documented after 2 weeks of culture in a growth chamber. A typical hyg ${ }^{\mathrm{R}}$ seedling had normal cotyledons, true leave and roots (Fig. 2A), while a hyg ${ }^{\mathrm{S}}$ seedling was arrested at early stage of germination and showed bleached cotyledons and radicle (Fig. 2D)
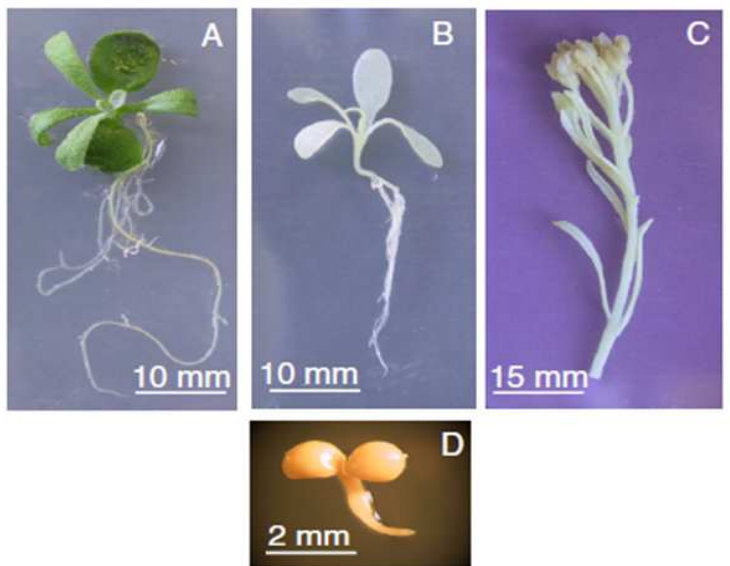

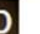
$\mathrm{mm}$

Fig. 1. Phenotype of 2 -week old $\mathrm{T} 1$ seedlings. A, a hygR seedling; B, a hygR seedling after GUS staining assay; C, a shoot branch from a hygR T1 plant after GUS staining assay; D, a hygs seedling killed by hygromycin

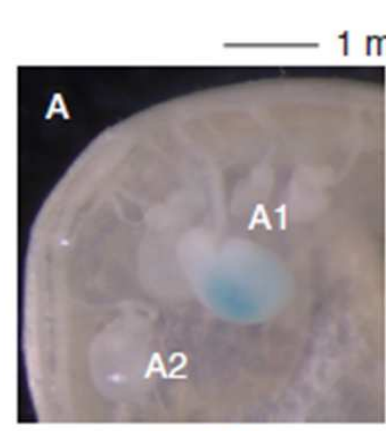

7 DAP

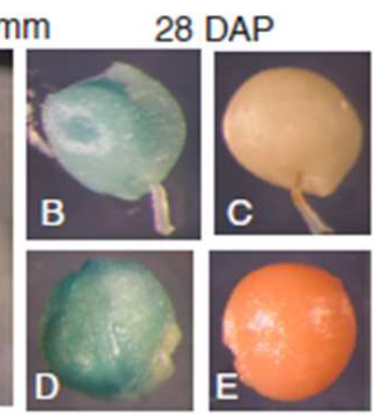

42 DAP
Fig. 2. GUS staining assay of developing $\mathrm{T} 1$ seeds. DAP stands for days after pollination. GUS+ seeds (A1, B and D) showing blue stain in embryos, while GUS- seeds (A2, C and D) showing no stain

\subsection{Tissue Specificity of PnapA}

To investigate the tissue specific activity of PnapA, we analyzed GUS activity in the shoot branches of primary (data not shown) and $\mathrm{T} 1$ plants (including leaves, stem and flower buds) and two-week old hyg ${ }^{\mathrm{R}} \mathrm{T} 1$ seedlings (including root, cotyledon, hypocotyls and leaves). None of these five lines showed any activity in these tissues (Fig. 1). When GUS activity was examined in developing $\mathrm{T} 1$ seeds of these five lines, we found that most seeds showed positive GUS staining and few seeds failed to take up the stain, consistent with the expectation of observing null segregants lacking the gusA transgene. The expression of GUS was detected as early as 7 Days After Pollination (DAP) and the expression persisted throughout the rest of seed development (mid-stages 21-35 DAP and late stage 42-49) (Fig. 2). This clearly indicated that the cloned PnapA had a seed specific expression pattern in L. fendleri.

\section{CONCLUSION}

We have constructed a binary vector, pGPro4-PnapA-gusA-eGFP to test PnapA activity in transgenic $L$. fendleri. By using histochemical analysis of the gusA gene activity, we confirmed that PnapA was active only in seeds. The PnapA can be used to express a target gene and to facilitate future research on genetic engineering of seed oil in L. fendleri.

\section{ACKNOWLEDGMENT}

The researchers thank Niu Dong and Debbie Laudencia-Chingcuanco for critical reading of the manuscript, Louisa Vang, XianFang Meng, Kumiko Johnson and Sebastian Morale for assisting with tissue culture and transformation of $L$. fendleri. Thanks are extended to Roger Timothy for kindly providing the pGPro4 vector. The work was supported by the United State Department of Agriculture, Agricultural Research Service, Current Research Information System (CRIS) Projects 5325-2100-016-00D. Mention of trade names or commercial products is solely for the purpose of providing specific information and does not imply recommendation or endorsement by the U.S. Department of Agriculture. USDA is an equal opportunity provider and employer.

\section{REFERENCES}

Baumlein, H., I. Nagy, R. Villarroel, D. Inze and U. Wobus, 1992. Cis-analysis of a seed protein gene promoter: The conservative RY repeat CATGCATG within the legumin box is essential for tissue-specific expression of a legumin gene. Plant J., 2: 233-239. PMID: 1338774 
Broun, P., S. Boddupalli and C. Somerville, 1998. A bifunctional oleate 12-hydroxylase: Desaturase from Lesquerella fendleri. Plant J., 13: 201-210. PMID: 9680976

Caupin, H.J., 1997. Products from Castor Oil: Past, Present and Future. In: Lipid Technologies and Applications, Gunstone, F.D. and F.B. Padley (Eds.)., Marcel Dekker, New York, ISBN: 10: 0824798384, pp: 787-795.

Chen, G.Q., 2011. Effective reduction of chimeric tissue in transgenics for the stable genetic transformation of Lesquerella fendleri. HortScience, 46: 86-90.

Chen, G.Q., R. Thilmony and J.T. Lin, 2011. transformation of Lesquerella fendleri with the new binary vector pGPro4-35S. OnLine J. Biol. Sci., 11: 90-95. DOI: 10.3844/ojbsci.2011.90.95

Crouch, M.L. and I.M. Sussex, 1981. Development and storage-protein synthesis in Brassica napus $\mathrm{L}$. embryos in vivo and in vitro. Planta, 153: 64-74.

Crouch, M.L., K.M. Tenbarge, A.E. Simon and R. Ferl, 1983. cDNA clones for Brassica napus seed storage proteins: evidence from nucleotide sequence analysis that both subunits of napin are cleaved from a precursor polypeptide. J. Mol. Appl. Genet., 2: 273-283. PMID: 6689334

Dierig, D.A., P.M. Tomasi and G.H. Dahlquist, 2001. Registration of WCL-LY2 high oil Lesquerella fendleri germplasm. Crop Sci., 41: 604-605.

Eccleston, V.S. and J.B. Ohlrogge, 1998. Expression of lauroyl-acyl carrier protein thioesterase in Brassica napus seeds induces pathways for both fatty acid oxidation and biosynthesis and implies a set point for triacylglycerol accumulation. Plant Cell, 10: 613-621. DOI: 10.1105/tpc.10.4.613

Ellerstrom, M., K. Stalberg, I. Ezcurra and L. Rask, 1996. Functional dissection of a napin gene promoter: Identification of promoter elements required for embryo and endosperm-specific transcription. Plant Mol. Biol., 32: 1019-1027. PMID: 9002600

Ezcurra, I., M. Ellerstrom, P. Wycliffe, K. Stalberg and L. Rask, 1999. Interaction between composite elements in the napA promoter: Both the B-box ABA-responsive complex and the $\mathrm{RY} / \mathrm{G}$ complex are necessary for seed-specific expression. Plant Mol. Biol., 40: 699-709. PMID: 10480393

Hellens, R.P., E. Anne Edwards, N.R. Leyland, S. Bean and P.M. Mullineaux, 2000. pGreen: A versatile and flexible binary $\mathrm{Ti}$ vector for Agrobacterium-mediated plant transformation. Plant Mol. Biol., 42: 819-832. DOI: 10.1023/A:1006496308160
Jefferson, R.A., T.A. Kavanagh and M.W. Bevan, 1987. GUS fusions: Beta-glucuronidase as a sensitive and versatile gene fusion marker in higher plants. EMBO J., 6: 3901-3907. PMID: 3327686

Josefsson, L.G., M. Lenman, M.L. Ericson and L. Rask, 1987. Structure of a gene encoding the $1.7 \mathrm{~S}$ storage protein, napin, from Brassica napus. J. Biol. Chem., 262: 12196-12201. PMID: 3624251

Lazo, G.R., P.A. Stein and R.A. Ludwig, 1991. A DNA transformation-competent Arabidopsis genomic library in Agrobacterium. Nature Biotechnol., 9: 963-967. DOI: 10.1038/nbt1091-963

Lelievre, J.M., L.O. Oliveira and N.C. Nielsen, 1992. 5'CATGCAT-3' elements modulate the expression of glycinin genes. Plant Physiol., 98: 387-391. PMID: 16668640

Skarjinskaia, M., Z. Svab and P. Maliga, 2003. Plastid transformation in Lesquerella fendleri, an oilseed Brassicacea. Transgenic Res., 12: 115-122. PMID: 12650530

Stalberg, K., M. Ellerstom, I. Ezcurra, S. Ablov and L. Rask, 1996. Disruption of an overlapping E-box/ABRE motif abolished high transcription of the napA storage-protein promoter in transgenic Brassica napus seeds. Planta, 199: 515-519. PMID: 8818291

Stalberg, K., M. Ellerstrom, L.G. Josefsson and L. Rask, 1993. Deletion analysis of a $2 \mathrm{~S}$ seed storage protein promoter of Brassica napus in transgenic tobacco. Plant Mol. Biol., 23: 671-683. PMID: 8251622

Topfer, R., N. Martini and J. Schell, 1995. Modification of plant lipid synthesis. Science, 268: 681-686. DOI: 10.1126/science.268.5211.681

Wang, W., C. Wang, B.L. Huang and B. Huang, 2008. Agrobacterium tumefaciens-mediated transformation of Lesquerella fendleri L., a potential new oil crop with rich lesquerolic acid. Plant Cell Tissue Organ Culture, 92: 165-171.

Xie, M., Y. He and S. Gan, 2001. Bidirectionalization of polar promoters in plants. Nature Biotechnol., 19: 677-679. DOI: 10.1038/90296

Yoo, S.Y., K. Bomblies, S.K. Yoo, J.W. Yang and M.S. Choi et al., 2005. The $35 \mathrm{~S}$ promoter used in a selectable marker gene of a plant transformation vector affects the expression of the transgene. Planta, 221: 523-530. PMID: 15682278 